\title{
Weronika Skowron-Mihaescu
}

Uniwersytet Marii Curie-Skłodowskiej w Lublinie weronikaskowron@poczta.fm

\section{Reforma Komitetu Praw Dziecka w świetle trzeciego Protokołu fakultatywnego do Konwencji o prawach dziecka}

\author{
Reform of the Committee on the Rights of the Child under \\ the Third Optional Protocol to the Convention on the Rights \\ of the Child
}

\section{STRESZCZENIE}

Jedną z umów należących do traktatowego systemu ochrony praw człowieka Narodów Zjednoczonych jest Konwencja o prawach dziecka przyjęta w dniu 20 listopada 1989 r. Stanowi ona główny dokument międzynarodowej ochrony praw dziecka. Na jej podstawie powstał organ mający na celu zapewnienie przestrzegania praw zawartych w Konwencji - Komitet Praw Dziecka. W późniejszych latach do Konwencji przyjęto trzy protokoły fakultatywne. Dwa pierwsze dotyczą prawa materialnego - Protokół fakultatywny do Konwencji o prawach dziecka w sprawie angażowania dzieci w konflikt zbrojny oraz Protokół fakultatywny do Konwencji o prawach dziecka w sprawie handlu dziećmi, dziecięcej prostytucji i dziecięcej pornografii (oba z dnia 25 maja 2010 r.). Trzeci Protokół fakultatywny do Konwencji o prawach dziecka w sprawie procedury składania zawiadomień z dnia 19 grudnia 2011 r. wprowadza reformę Komitetu Praw Dziecka przez procedurę indywidualnych i międzypaństwowych zawiadomień. Treść niniejszego opracowania dotyczy analizy wprowadzonych zmian i stanowi próbę oceny ich praktycznego zastosowania.

Słowa kluczowe: międzynarodowa ochrona praw człowieka; ochrona praw dziecka; Konwencja o prawach dziecka; Komitet Praw Dziecka; reforma

\section{PODSTAWY MIĘDZYNARODOWEJ OCHRONY PRAW DZIECI}

Międzynarodowa ochrona praw dziecka została zapoczątkowana w XIX w. ${ }^{1}$ Później standardy w tym zakresie tworzyła Liga Narodów, a po II wojnie świato-

\footnotetext{
${ }^{1}$ M. Balcerek, Międzynarodowa ochrona praw dziecka, Warszawa 1988, s. 59.
} 
wej - Organizacja Narodów Zjednoczonych. Po wielu latach prac w dniu 20 listopada 1989 r. Zgromadzenie Ogólne ONZ uchwaliło pierwszy po II wojnie światowej wiążący dokument $\mathrm{w}$ dziedzinie ochrony praw dziecka² ${ }^{2}$ Konwencję o prawach dziecka ${ }^{3}$. Od tego momentu Konwencja ta wpisuje się w uniwersalny traktatowy system ochrony praw człowieka ONZ. Konwencja o prawach dziecka, ze względu na podstawową rolę, jaką pełni, nazywana jest Międzynarodową Konstytucją Praw Dziecka ${ }^{4}$. J. Grant - dyrektor wykonawczy UNICEF-u w latach 80. $\mathrm{XX}$ w., powiedzial, że ,stanowi ona twardy fundament dla nowej etyki na rzecz dzieci, etyki, która definiuje dzieci jako jednostki posiadające niezbywalne prawa o nie mniejszej wartości niż prawa dorosłych"s.

W Konwencji o prawach dziecka przewidziano utworzenie organu kontrolnego w celu nadzorowania przestrzegania Konwencji przez państwa-strony - Komitetu Praw Dziecka. W późniejszych latach do Konwencji przyjęto trzy protokoły dodatkowe. Dwa pierwsze rozwijają postanowienia o charakterze materialnoprawnym: Protokół fakultatywny do Konwencji o prawach dziecka dotyczący włączania dzieci w konflikt zbrojny ${ }^{6}$ i Protokół fakultatywny do Konwencji o prawach dziecka dotyczący sprzedaży dzieci, dziecięcej prostytucji i dziecięcej pornografii (oba z dnia 25 maja 2000 r.) 7 . Trzeci Protokół fakultatywny do Konwencji o prawach dziecka w sprawie procedury składania zawiadomien ${ }^{8} \mathrm{z}$ dnia 19 grudnia 2011 r. dotyczy reformy proceduralnej Komitetu Praw Dziecka.

\section{KOMITET PRAW DZIECKA - SKŁAD I DZIAŁALNOŚĆ}

Komitet Praw Dziecka, tak jak inne organy działające w ramach traktatowego systemu ochrony praw człowieka, nie ma statutu w formie odrębnego dokumentu.

\footnotetext{
${ }^{2}$ Konwencja o prawach dziecka z dnia 20 listopada 1989 r. przyjęta w Nowym Jorku (Dz.U. z 1991 r., nr 120, poz. 526), tekst w: A. Przyborowska-Klimczak, Prawo międzynarodowe publiczne. Wybór dokumentów, Lublin 2008, s. 168-184.

${ }^{3}$ A Łopatka, Konwencja praw dziecka w Polsce, [w:] Prawa dziecka. Deklaracja i rzeczywistość, red. J. Bińczycka, Kraków 1999, s. 17.

${ }^{4}$ Konwencja o prawach dziecka. Wybrane zagadnienia prawne i socjalne, red. T. Smyczyński, Warszawa 1994, s. 1.

${ }^{5}$ Cyt. za: A. Łopatka, op. cit., s. 17.

${ }^{6}$ Protokół fakultatywny do Konwencji o prawach dziecka w sprawie angażowania dzieci w konflikt zbrojny z dnia 25 maja 2000 r. przyjęty w Nowym Jorku (Dz.U. z 2007 r., nr 76, poz. 464), tekst w: A. Przyborowska-Klimczak, op. cit., s. 185-189.

${ }^{7}$ Protokół fakultatywny do Konwencji o prawach dziecka w sprawie handlu dziećmi, dziecięcej prostytucji i pornografii z dnia 25 maja 2000 r. przyjęty w Nowym Jorku (Dz.U. z 2007 r., nr 91, poz. 608), tekst w: A. Przyborowska-Klimczak, op. cit., s. 190-196.

${ }^{8}$ Protokół fakultatywny do Konwencji o prawach dziecka w sprawie procedury składania zawiadomień z dnia 19 grudnia 2011 r. przyjęty w Nowym Jorku, tekst w: P. Jaros, M. Michalak, Prawa dziecka. Dokumenty ONZ, Warszawa 2015, s. 310-320.
} 
Za akt powołania tego organu, w którym zawarto również zasady dotyczące kształtowania jego składu i organizacji, należy uznać odpowiednie postanowienia Konwencji o prawach dziecka zawarte w jej drugiej części ${ }^{9}$. Komitet oficjalnie zaczął funkcjonować w dniu, w którym weszła w życie Konwencja o prawach dziecka, tj. 2 września 1990 r. ${ }^{10}$ Pierwszą sesję odbył w Genewie w dniach od 10 września do 18 października $1991 \mathrm{r}^{11}$

Początkowo w skład Komitetu wchodziło 10 ekspertów. W dniu 12 grudnia 1995 r. wprowadzono poprawkę, na podstawie której liczba ekspertów wzrosła do $18^{12}$. Są oni wybierani na czteroletnią kadencję ${ }^{13}$. Zmiany tej dokonano w celu usprawnienia pracy Komitetu. W Komitecie, oprócz zasiadających ekspertów, pracują także funkcjonariusze. KPD ma główną siedzibę w Nowym Jorku, gdzie zwykle odbywają się jego posiedzenia. Co do zasady Komitet spotyka się raz do roku. W praktyce jednak corocznie odbywają się trzy sesje Komitetu - w styczniu, maju i wrześniu ${ }^{14}$. Konwencja o prawach dziecka tworzy ogólne ramy działania KPD. Zgodnie z art. 43 ust. 8 Konwencji ${ }^{15}$ Komitet ustala zasady swojego funkcjonowania. Pierwsze tymczasowe reguły zostały ustanowione przez Komitet podczas jego pierwszej sesji w $1990 \mathrm{r}^{16}$

Można wyróżnić sześć form działalności KPD ${ }^{17}: 1$ ) analizowanie sprawozdań państw-stron Konwencji, 2) publikację raportów, 3) wydawanie zaleceń, 4) wydawanie komentarzy ogólnych, 5) organizowanie Dni Debat Ogólnych ${ }^{18}$, 6) wspólpracę z innymi organami ONZ i organizacjami wyspecjalizowanymi. Najnowsza siódma procedura badania zawiadomień międzypaństwowych i indywidualnych jest przewidziana w trzecim Protokole fakultatywnym do Konwencji o prawach dziecka.

${ }^{9}$ A. Przyborowska-Klimczak, op. cit., s. 185-189.

${ }^{10} \mathrm{~J}$. Kondratiewa-Bryzik, Poczatek prawnej ochrony życia ludzkiego w świetle standardów międzynarodowych, Warszawa 2009, s. 91.

${ }^{11}$ A Łopatka, op. cit., s. 29.

${ }^{12}$ Convention on the Rights of the Child Adopted by the General Assembly of the United Nations on 20 November 1989, https://treaties.un.org/doc/Publication/CN/1995/CN.138.1995-Eng.pdf [dostęp: 20.09.2017].

${ }^{13}$ G. Michałowska, Międzynarodowa ochrona praw dziecka, Warszawa 2016, s. 122.

${ }^{14}$ Ibidem.

${ }^{15}$ A. Przyborowska-Klimczak, op. cit., s. 185-189.

${ }^{16}$ A Łopatka, op. cit., s. 29.

${ }^{17}$ M. Prucnal, Komitet Praw Dziecka i jego zadania, [w:] Konwencja o prawach dziecka. Wybór zagadnień (artykuly i komentarze), red. S. Stadniczeńko, Warszawa 2015, s. 356-357.

${ }^{18}$ J. Kondratiewa-Bryzik, op. cit., s. 91-92. 


\section{GENEZA TRZECIEGO PROTOKOŁU FAKULTATYWNEGO DO KONWENCJI O PRAWACH DZIECKA}

KPD prowadził działalność w sześciu wyżej wymienionych formach od 1990 r. W związku z tym, że Konwencja o prawach dziecka i Komitet, który powstał na jej podstawie, są częścią traktatowego systemu ochrony praw człowieka ONZ, działalność KPD bardzo często jest porównywana z innymi tego typu organami. Na podstawie konkretnych przykładów ukazujących faktyczną sytuację dzieci w różnych częściach świata oraz raportów publikowanych m.in. przez UNICEF $^{19} \mathrm{i}$ inne organizacje wyspecjalizowane ONZ, społeczność międzynarodowa zauważyła niedostateczny poziom ochrony praw dziecka w dotychczasowym systemie. $Z$ tego powodu zdecydowano, że poza rozwojem praw dziecka w postaci norm prawa materialnego potrzebny jest też rozwój i wzmocnienie uregulowań proceduralnych. Postanowiono zatem przyjąć trzeci Protokół dodatkowy do Konwencji o prawach dziecka dotyczący KPD i jego działalności. Sprawa wprowadzenia do procedur KPD procedury zawiadomień została podjęta w 1999 r. Wtedy Komitet ogłosił, że rozważy wszczęcie dyskusji o mechanizmie indywidualnych zawiadomień w celu lepszego zapewnienia dostępności środków ochrony praw dziecka na poziomie międzynarodowym. Komitet zachęcił państwa-strony Konwencji do wspierania wysiłków w tym zakresie. KPD sam nie był jednak przekonany o konieczności wprowadzenia takiej procedury i dopiero 10 lat później zdecydował się na rozpoczęcie prac nad trzecim Protokołem do Konwencji o prawach dziecka. W 2007 r. przedstawiciele wielu organizacji pozarządowych ponownie zgłosili potrzebę zmian na forum Komitetu, które mogłyby zostać wprowadzone w okrągłą 20. rocznicę przyjęcia Konwencji o prawach dziecka. W 2008 r. podczas 48. sesji KPD podjęto ostatecznie decyzję o wprowadzeniu procedury zawiadomień w formie trzeciego Protokołu fakultatywnego do Konwencji. Rozpoczęły się szerokie konsultacje, zainicjowane przez Słowację i Słowenię ${ }^{20}$. Zadanie przygotowania projektu zostało powierzone przewodniczącemu grupy roboczej, którym został D. Stefánek ${ }^{21}$. Pierwsza sesja grupy roboczej przygotowującej protokół odbyła się w dniach 16-18 grudnia 2009 r. w Genewie ${ }^{22}$. Drugie posiedzenie grupy roboczej zostało podzielone na dwa spo-

${ }^{19}$ UNICEF, Research and reports, www.unicef.org/reports [dostęp: 20.09.2017].

${ }^{20} \mathrm{Y}$. Lee, Communications procedure under the Convention on the Rights of the Child: $3^{\text {rd }}$ Optional Protocol, "International Journal of Children's Rights" 2010, Vol. 18(4), DOI: https:// doi.org/10.1163/157181810X527239, s. 569.

${ }^{21}$ A. Szarek-Zwijacz, Protokót fakultatywny do Konwencji o prawach dziecka dotyczacy procedury zawiadomień - rzeczywiste wzmocnienie ochrony praw dzieci?, [w:] Odpowiedzialność międzynarodowa w zwiazku z naruszeniami praw człowieka i międzynarodowego prawa humanitarnego, red. M. Balcerzak, J. Kapelańska-Pręgowska, Toruń 2016, s. 166.

${ }^{22}$ T. Buck, M. Wabwile, The Potential and Promise of Communications Procedures under the 
tkania: pierwsze odbyło się w grudniu 2010 r., a drugie - w lutym 2011 r. ${ }^{23}$ Ostateczny tekst uzgodniono i przygotowano $\mathrm{w}$ dniu 17 czerwca $2011 \mathrm{r} .{ }^{24}$ Prace zakończyły się przyjęciem Protokołu w dniu 19 grudnia $2011 \mathrm{r}^{25} \mathrm{i}$ otwarciem go do podpisu w dniu 28 lutego $2012 \mathrm{r}^{26}$

Zgodnie z art. 19 Protokołu $^{27}$ wszedł on w życie - po ratyfikacji go przez minimum 10 państw - 14 kwietnia 2014 r. ${ }^{28}$ Stronami trzeciego Protokołu do Konwencji o prawach dziecka, podobnie jak w wypadku dwóch pierwszych Protokołów dodatkowych, mogą być tylko państwa-strony Konwencji o prawach dziecka. Biorąc pod uwagę liczbę stron Konwencji z dnia 20 listopada 1989 r. oraz dwóch późniejszych Protokołów, liczba stron Protokołu z 2011 r. jest zdecydowanie mniejsza, a tempo procesu jego ratyfikacji przez poszczególne państwa wolniejsze. Obecnie są 34 strony trzeciego Protokołu dodatkowego ${ }^{29}$. Pierwszymi państwami, które dokonały ratyfikacji, były Tajlandia i Gabon w dniu 25 września 2012 r., a ostatnim państwem, które do tej pory ratyfikowało Protokół, jest Chorwacja, która dokonała tego 18 kwietnia 2017 r. ${ }^{30}$ Należy dodać, że 51 państw podpisało Protokół, nie ratyfikując go. Polska podpisała Protokół w dniu 30 września 2013 r. ${ }^{31} \mathrm{~W}$ dniu 27 sierpnia 2014 r. Rzecznik Praw Dziecka M. Michalak zwrócił się z prośbą do Rady Ministrów o jak najszybsze ratyfikowanie tego Protokołu, podkreślając jego duże znaczenie dla rozwoju stopnia ochrony praw dziecka w Polsce i na świecie ${ }^{32}$. W tej sprawie były kierowane również zapytania do rządu ze strony posłów polskiego Sejmu. Do tej pory jednak Polska nie ratyfikowała trzeciego Protokołu.

Third Protocol to the Convention on the Rights of the Child, "International Human Rights Law Review" 2013, Vol. 2, s. 208.

${ }^{23}$ G. de Beco, The Optional Protocol to the Convention on the Rights of the Child on a Communications Procedure: Good News?, "International Human Rights Law Review" 2013, No. 367, s. 370 .

${ }^{24}$ Ibidem, s. 373.

${ }^{25}$ United Nations Treaty Series, Chapter IV: Human Rights, https://treaties.un.org/Pages/ViewDetails.aspx?src=TREATY\&mtdsg_no=IV-11-d\&chapter=4\&clang=_en [dostęp: 20.09.2017].

${ }^{26}$ T. Buck, M. Wabwile, op. cit., s. 208.

${ }^{27}$ M. Prucnal, op. cit., s. 318-319.

${ }^{28}$ United Nations Treaty Series, Chapter IV: Human Rights.

${ }^{29}$ Są to: Albania, Andora, Argentyna, Belgia, Boliwia, Chile, Czarnogóra, Czechy, Dania, Finlandia, Francja, Gabon, Gruzja, Hiszpania, Irlandia, Kostaryka, Liechtenstein, Luksemburg, Monako, Mongolia, Niemcy, Panama, Paragwaj, Peru, Portugalia, Salwador, Samoa, Słowacja, Tajlandia, Ukraina, Urugwaj i Włochy. Ibidem.

${ }^{30}$ Ibidem.

${ }^{31}$ Ibidem.

${ }^{32}$ RPD, W sprawie ratyfikacji III Protokotu Fakultatywnego do Konwencji o Prawach Dziecka, http://brpd.gov.pl/aktualnosci-wystapienia-generalne/w-sprawie-ratyfikacji-iii-protokolu-fakulta tywnego-do-konwencji--0 [dostęp: 07.07.2017]. 


\section{ZMIANY W DZIAŁALNOŚCI KPD - PROCEDURY ZAWIADOMIEŃ I POSTĘPOWANIE WYJAŚNIAJĄCE}

Protokół wprowadza istotną zmianę dotyczącą działalności KPD. Ustanawia on procedurę zawiadomień jako kolejną formę jego działalności. Warto tu podkreślić, że z sześciu wymienionych wyżej form proceduralnych korzystają wszystkie państwa, które są stronami Konwencji o prawach dziecka, natomiast procedura, która weszła w życie w 2014 r., jest zarezerwowana tylko dla państw-stron trzeciego Protokołu dodatkowego do Konwencji o prawach dziecka. Procedura ta nazwana jest $w$ tytule Protokołu procedurą zawiadomień ${ }^{33}$. Stanowi ona novum dla KPD, lecz funkcjonowała już w traktatowym systemie ochrony praw człowieka ONZ ${ }^{34}$. Przez jej wprowadzenie państwa zbliżyły KPD do pierwszego, osiągającego największe sukcesy, Komitetu Praw Człowieka, powołanego na podstawie Międzynarodowego Paktu Praw Obywatelskich i Politycznych z dnia 19 grudnia 1966 r. $^{35}$ Głównym celem tego Protokołu jest jak najlepsze zabezpieczenie interesów dziecka, uwzględniające jego prawa i poglądy. Komitet może odmówić wszczęcia procedury zawiadomień, jeśli uzna się za niewłaściwy w sprawie z uwagi na to, że dane państwo nie było w momencie wszczęcia postępowania stroną Protokołu ${ }^{36}$. Podstawową zasadą Protokołu, zawartą już w Konwencji o prawach dziecka, jest klauzula dobra dziecka ${ }^{37}$. Stanowi ona nadrzędną zasadę wszelkich działań podejmowanych w ramach procedury skargowej przed Komitetem Praw Dziecka $^{38}$. Jest również potwierdzeniem statusu dziecka jako podmiotu wszelkich praw wynikających z jego przyrodzonej godności ${ }^{39}$.

Procedury zawiadomień w KPD można podzielić na procedurę zawiadomień indywidualnych i procedurę zawiadomień międzypaństwowych. Procedura zawiadomień indywidualnych ${ }^{40}$ polega na tym, że dana osoba lub grupa osób, które uważają, że ich prawa zostały naruszone, składa o tym zawiadomienie do KPD. Możliwe jest również wyrażenie zgody na działanie osoby trzeciej w imieniu bezpośrednio pokrzywdzonego. W Protokole zostały określone przesłanki niedo-

${ }^{33}$ Tekst Protokołu: RPD, www.brpd.gov.pl [dostęp: 07.05.2016].

${ }^{34}$ P. Jaros, Trzeci Protokót Fakultatywny do Konwencji - komentarz, [w:] Konwencja o prawach dziecka. Wybór zagadnień..., s. 363-364.

${ }^{35}$ Międzynarodowy Pakt Praw Obywatelskich i Politycznych z dnia 19 grudnia 1966 r. przyjęty w Nowym Jorku (Dz.U. z 1997 r., nr 38, poz. 67), tekst w: A. Przyborowska-Klimczak, op. cit., s. $185-189$.

${ }^{36}$ P. Jaros, M. Michalak, op. cit., s. 313.

${ }^{37}$ W. Stojanowska, Dobro dziecka jako instrument wyktadni norm Konwencji o prawach dziecka oraz prawa polskiego i jako dyrektywa jego stosowania, [w:] Konwencja o prawach dziecka. Wybrane zagadnienia prawne i socjalne, red. T. Smyczyński, Warszawa 1999, s. 81.

${ }^{38}$ P. Jaros, M. Michalak, op. cit., s. 311.

${ }^{39}$ T. Buck, M. Wabwile, op. cit., s. 210.

${ }^{40}$ P. Jaros, M. Michalak, op. cit., s. 312. 
puszczenia takiej skargi do dalszego procedowania. KPD nie dopuszcza skargi składanej anonimowo, w innej formie niż pisemna, gdy jest ona niezgodna z Konwencją o prawach dziecka, gdy stanowi nadużycie prawa, jeśli skarga w tej sprawie była już rozpatrywana lub gdy wszystkie konieczne środki krajowe nie zostały wyczerpane. Ponadto Komitet odrzuca skargę, gdy jest ona jego zdaniem niedopuszczalna, nieuzasadniona lub dotyczy faktów, które miały miejsce przed wejściem w życie Konwencji. Jeśli chodzi o wyczerpanie środków krajowych, Protokół nie precyzuje, jakie środki powinny zostać wykorzystane. Zależy to od porządku prawnego danego państwa. Protokół wskazuje tylko na roczny termin, w ciągu którego składający wniosek, po skorzystaniu z dopuszczalnych krajowych form odwoławczych, ma obowiązek zgłosić zawiadomienie do KPD. Komitet po otrzymaniu zawiadomienia informuje o tym państwo, którego dotyczy zawiadomienie. Państwo to ma 6 miesięcy na złożenie wyjaśnień i oświadczeń w danej sprawie. Jeśli z przedstawionej sprawy wynika, że od momentu zawiadomienia do końca procedury szkoda domniemanej ofiary może się zwiększyć, wtedy Komitet na tym etapie ma prawo zastosować środki tymczasowe. Zastosowanie takich środków w żadnym wypadku nie może być jednoznacznie interpretowane jako stwierdzenie przez KPD naruszenia postanowień Konwencji i Protokołów dodatkowych ${ }^{41}$. Dalszy przebieg postępowania zależy od rodzaju sprawy i naruszenia prawa. Komitet może zaoferować dobre usługi ${ }^{42}$ i umożliwić państwu oraz ofierze polubowne rozstrzygnięcie sprawy. Jeżeli wymaga tego charakter sprawy, Komitet bada ją na posiedzeniu zamkniętym z zastosowaniem szybszego trybu procedowania. Po tym etapie kieruje do państwa swoją opinię w sprawie. Państwo ma 6 miesięcy na ustosunkowanie się do tej opinii oraz obowiązek wnikliwie rozważyć sprawę i przesłać Komitetowi swoją ostateczną odpowiedź.

Druga procedura - procedura zawiadomień międzypaństwowych ${ }^{43}$ - charakteryzuje się przede wszystkim tym, że państwo-strona Konwencji o prawach dziecka ma prawo domagać się uznania, że inne państwo-strona nie wypełnia należycie swoich obowiązków wynikających z Konwencji. Można wyróżnić trzy zasadnicze motywy, którymi państwo-strona może kierować się, inicjując tę procedurę. Po pierwsze, mogą być to względy czysto polityczne. W takiej sytuacji wątpliwa staje się faktyczna potrzeba zwrócenia uwagi na tylko i wyłącznie naruszenie przez inne państwo-stronę postanowień w zakresie ochrony praw dziecka. Istnieje bowiem obawa traktowania tego mechanizmu jedynie jako instrumentu w bieżącej polityce. Po drugie, państwo skarżące może mieć swój interes w tym, żeby zainicjować takie postępowanie (np. gdy łamane są prawa dziecka w państwie bezpośrednio graniczącym lub też w takim, w którym zamieszkuje znaczna

\footnotetext{
${ }^{41}$ T. Buck, M. Wabwile, op. cit., s. 213.

${ }^{42}$ W. Góralczyk, S. Sawicki, Prawo międzynarodowe publiczne w zarysie, Warszawa 2009, s. 335.

${ }^{43}$ P. Jaros, M. Michalak, op. cit., s. 315.
} 
pod względem liczebności mniejszość obywateli państwa skarżącego). Po trzecie, upatrując powodu, dla którego dane państwo-strona decyduje się zwrócić uwagę na łamanie praw dziecka w innym państwie, można odnieść się na zasadzie analogii do jednej z podstawowych instytucji prawa rzymskiego actio popularis ${ }^{44}$. Nieco ją modyfikując, należy stwierdzić, że każde państwo-strona trzeciego Protokołu, jako aktywny uczestnik stosunków międzynarodowych i stojąc na straży przestrzegania prawa międzynarodowego, w tym wypadku dotyczącego ochrony praw dziecka, ma uprawnienie, a w niektórych przypadkach obowiązek, zwrócenia uwagi na nieprzestrzeganie postanowień przez inne państwo-stronę, do kompetentnego organu - KPD. W praktyce w drodze takiej procedury składane są skargi na dyskryminację dzieci innego obywatelstwa, brak azylu dla dzieci deportowanych imigrantów lub nielegalność stosowania kar cielesnych. Należy podkreślić, że po wniosku strony Konwencji i Protokołu, inicjującym postępowanie przed KPD, państwo, którego skarga dotyczy, ma obowiązek złożyć oświadczenie, że uznaje właściwość KPD w tej sprawie. Postępowanie to nie jest zatem automatycznym zobowiązaniem wynikającym z ratyfikowania trzeciego Protoko$\mathfrak{u u}^{45}$. Oświadczenie takie jest składane Sekretarzowi Generalnemu ONZ w formie pisemnej notyfikacji. Może ono zostać przez państwo cofnięte na każdym etapie procedury. Wydaje się jednak, że procedura zawiadomień powinna być poprzedzona dialogiem dyplomatycznym i próbą dojścia do konsensusu, bez formalnego udziału KPD. Jeżeli postępowanie w danym stanie faktycznym okaże się niezbędne, i w tym wypadku Komitet oferuje państwom dobre usługi, które mają zmierzać do jak najszybszego i polubownego załatwienia sprawy. Podkreślić trzeba, że w takim wypadku rola KPD pozostaje bierna i sprowadza się wyłącznie do funkcji quasi-mediatora zapewniającego stronom konfliktu tylko odpowiednie warunki w celu jego rozwiązania ${ }^{46}$. Warto wziąć pod uwagę fakt, że wprowadzenie tej procedury może paradoksalnie doprowadzić do naturalnego zacieśnienia współpracy między poszczególnymi państwami-stronami. KPD mógłby stać się forum wymiany różnych poglądów, a w konsekwencji - poszukiwania wspólnych rozwiązań. System skarg może poza tym skłonić poszczególne państwa-strony do dokonania przeglądu i zreformowania swojej polityki wewnętrznej w obszarze ochrony praw dziecka.

Obok dwóch wymienionych wyżej procedur KPD może prowadzić też postępowanie wyjaśniające. Dzieje się tak w sytuacji, w której Komitet otrzyma wiarygodną informację, która wskazuje na poważne i systematyczne naruszenie któregokolwiek prawa wynikającego z Konwencji lub Protokołów dodatkowych. Ko-

${ }^{44}$ M. Kuryłowicz, A. Wiliński, Prawo rzymskie prywatne. Zarys wykładu, Warszawa 2008, s. 133, 279.

${ }^{45}$ T. Buck, M. Wabwile, op. cit., s. 216.

${ }^{46}$ Ibidem, s. 214. 
mitet wyznacza do pracy nad daną sprawą jednego lub więcej członków. Mają oni za zadanie prowadzić postępowanie, które może obejmować także wizytę w państwie, którego sprawa dotyczy i zbadanie sprawy na miejscu. Działania te są prowadzone poufnie, ale we współpracy z państwem wizytującym. Komitet po przeprowadzeniu postępowania przedstawia państwu swoje ustalenia, uwagi i zalecenia. Państwo ma 6 miesięcy na złożenie odpowiedzi. Komitet może również zwrócić się z prośbą o przedstawienie przez państwo informacji oraz sprawozdania z poczynionych kroków i zastosowanych środków. Wydaje się, że nic nie stoi na przeszkodzie, aby taka odpowiedź lub informacje znalazły się w okresowym sprawozdaniu, które każde państwo-strona Konwencji o prawach dziecka i jej Protokołów dodatkowych ma obowiązek składać, o ile zostanie zachowany termin przewidziany w procedurze skargi na podstawie trzeciego Protokołu fakultatywnego ${ }^{47}$. Na koniec procedury KPD przekazuje innym instytucjom i organom ONZ sprawozdanie w związku z prowadzoną sprawą, jeżeli w trakcie postępowania prosił dany organ lub instytucję o udzielenie pomocy. Sprawozdanie z postępowania wyjaśniającego jest dołączane do sprawozdania składanego przez KPD Zgromadzeniu Ogólnemu ONZ. W ramach postępowania wyjaśniającego, poza podstawowym zadaniem, jakim jest kontrola przestrzegania praw dziecka w danym państwie, KPD ma możliwość popularyzowania najlepszych praktyk związanych z zagadnieniem ochrony praw dziecka oraz promowania i rozwijania wśród państw zdolności negocjacyjnych i mediacyjnych. Przedstawiając tę procedurę, warto zwrócić uwagę na jej aspekt organizacyjny. Bez wątpienia, aby była rzetelnie i skutecznie przeprowadzana, wymaga ona znacznych środków finansowych na pokrycie podróży, pracy na miejscu oraz kosztów logistyki i przygotowywanej specjalnie infrastruktury.

\section{PRÓBA OCENY TRZECIEGO PROTOKOŁU FAKULTATYWNEGO DO KONWENCJI O PRAWACH DZIECKA}

Trzeci Protokół fakultatywny do Konwencji o prawach dziecka wszedł w życie 2 lata temu ${ }^{48}$. Trudno jest zatem dokonać pogłębionej oceny jego funkcjonowania $\mathrm{w}$ praktyce.

Zdaniem P. Gerber procedura zawiadomień wykazuje pewne wady ${ }^{49}$. Wnoszone zawiadomienia mogą dotyczyć wyłącznie naruszeń, które miały miejsce po wejściu w życie Protokołu w stosunku do danego państwa. Istnieje jeden wyjątek. W procedurze zawiadomień może być badany przypadek, który miał wpraw-

\footnotetext{
${ }^{47}$ Ibidem, s. 215.

${ }^{48}$ United Nations Treaty Series, Chapter IV: Human Rights.

${ }^{49}$ P. Gerber, The New Optional Protocol to the Convention on the Rights of the Child. 10 things you should know, "Alternative Law Journal" 2012, Vol. 32(2), s. 111-115.
} 
dzie miejsce przed wejściem w życie Protokołu, ale skutki tego naruszenia trwały po wejściu Protokołu w życie. Instrument ten nie będzie zapewniał pomocy przy wszelkich wypadkach łamania praw człowieka w świetle obowiązującej Konwencji o prawach dziecka i jej protokołów dodatkowych. Autorka przytacza jednak argument, który przemawia za tym, że trzeci Protokół fakultatywny jest ważnym krokiem zmierzającym do wzmocnienia ochrony praw dziecka. Świadczy o tym wprowadzenie możliwości składania zawiadomienia przez dziecko, którego prawa zostały naruszone. Mimo to wniesienie takiego zawiadomienia może być dokonane przez rodziców, przedstawicieli ustawowych lub prawników w imieniu dziecka, lecz nie jest to konieczne. Trzeba bowiem zwrócić uwagę na fakt, że często rodzice albo opiekunowie mogą być osobami zaangażowanymi w konflikt, co w praktyce uniemożliwiałoby złożenie takiej skargi, gdyby nie wprowadzono prawa samego dziecka w tym zakresie ${ }^{50}$.

Zdaniem P. Limsira Protokół wprowadzający procedurę zawiadomień stanowi ważny krok naprzód w zakresie promowania praw dziecka ${ }^{51}$. Dużą wartością Protokołu jest to, że nie został on opracowany jedynie w celu powielenia istniejących wcześniej procedur, ale wprowadzono go, aby faktycznie dążyć do zwiększenia efektywności zasady jak najlepszego zabezpieczenia interesów dziecka ${ }^{52}$.

W przygotowanych dotychczas, jeszcze nielicznych, opracowaniach na temat trzeciego Protokołu fakultatywnego do Konwencji o prawach dziecka wielu autorów podkreśla, że dla lepszego zrozumienia zmian, jakie dla funkcjonowania KPD wprowadza trzeci Protokół, istotne jest rozważenie postanowień proponowanych w trakcie prac przygotowawczych, które ostatecznie nie znalazły się w treści Protokołu, a które uczyniłyby nową procedurę skarg przed Komitetem Praw Dziecka bardziej skuteczną. Jednym z najpoważniejszych zarzutów, na który warto zwrócić uwagę, jest brak uprawnienia do złożenia petycji przez krajowe instytucje zajmujące się ochroną praw człowieka, w tym organizacje pozarządowe ${ }^{53}$, które mogłyby składać tzw. skargi zbiorowe bez konieczności identyfikacji konkretnego dziecka jako ofiary naruszenia praw dziecka wynikającego z Konwencji i Protokołów dodatkowych. Podczas pierwszego spotkania grupy roboczej w grudniu 2009 r. przedstawiono stanowisko organizacji pozarządowych co do poszerzenia ich kompetencji w ramach przyjmowanej właśnie procedury skargi zbiorowej. Rozszerzenie to miałoby też objąć krajowe organizacje zajmujące się ochroną praw dziecka. Mimo że większość delegacji uznała, iż procedura skargi w świetle trzeciego Protokołu stanie się użytecznym narzędziem przyczyniającym się do rozwoju ochrony praw dziecka, propozycje organizacji pozarządo-

\footnotetext{
${ }^{50}$ Ibidem, s. 114-115.

${ }^{51}$ P. Limsira, Optional Protocol to the Convention on the Rights of the Child on a Communications Procedure, "Journal of East Asia and International Law" 2013, Vol. 1(8), s. 290.

${ }^{52}$ Ibidem, s. 291.

${ }^{53}$ G. de Beco, op. cit., s. 381.
} 
wych wprowadzających skargi zbiorowe nie zostały przyjęte. Organizacje w odpowiedzi na negatywną ocenę ich wprowadzenia podkreśliły, że w tak delikatnym obszarze praw człowieka mechanizm skargi powinien być dodatkowo wzmacniany i pójść krok dalej niż dotychczasowe podobne procedury w ramach traktatowego systemu ochrony praw człowieka ONZ ${ }^{54}$. Propozycja skarg zbiorowych miała być kolejnym stopniem rozwoju w dziedzinie praw dziecka pomimo tego, że zarzucono jej podobieństwo do procedury dochodzeniowej.

Pomysłodawcy podkreślali poza tym różnice i korzyści mogące wpłynąć na ochronę praw dziecka po wprowadzeniu skarg zbiorowych. Przede wszystkim podstawą wszczęcia takiego postępowania byłoby już jedynie ,powtarzające się" naruszenie, bez przymiotu jego wagi ${ }^{55}$. Uznano bowiem, że byłoby to obniżenie progu dopuszczalności zainicjowania postępowania przez KPD w celu ustalenia nieprzestrzegania $\mathrm{w}$ danym państwie-stronie praw dziecka. Zwiększyłoby to praktyczną dostępność do KPD i zlikwidowałoby konieczność każdorazowej oceny przez KPD danej sprawy pod kątem powagi naruszenia postanowień Konwencji i jej Protokołów ${ }^{56}$. Poza tym podkreślano, że taka procedura stanowiłaby wypełnienie luki w dotychczasowej ochronie praw dziecka w ramach ONZ oraz mogłaby pełnić funkcję zapobiegawczą ${ }^{57}$. Realizowałoby się to przez zmniejszenie liczby spraw przez KPD, ponieważ odpowiedź KPD na skargę zbiorową kompleksowo regulowałaby kwestię powtarzających się najczęściej naruszeń Konwencji praw dziecka i jej Protokołów dodatkowych w danym państwie-stronie. Zaletą tej procedury byłby również brak konieczności bezpośredniego angażowania ofiar w procedurę zawiadomienia o naruszeniu postanowień Konwencji o prawach dziecka i jej Protokołów dodatkowych. Umożliwiałaby ona też rozpatrzenie przez KPD spraw, które w innym wypadku nie mogłyby trafić przed jego skład ${ }^{58}$.

Odrzucenie wyżej opisanej propozycji, firmowanej głównie przez organizacje pozarządowe, oraz niedopuszczenie do końcowego etapu prac przedstawicieli UNICEF-u odzwierciedliło faktyczny prymat władz państwowych i KPD w negocjowaniu ostatecznego tekstu trzeciego Protokołu oraz oznaczało odejście od tradycyjnego silnego wpływu pozapaństwowych jednostek na kształtowanie się dotychczasowego prawa w obszarze ochrony praw dziecka. Uzasadnić to można tym, że trzeci Protokół w większym stopniu niż Konwencja i dwa poprzednie Protokoły dodatkowe ingeruje w kompetencje państw-stron, co potwierdza też dość niski stan ratyfikacji trzeciego Protokołu dodatkowego.

Ponadto niektóre delegacje przedstawiły pomysł ustanowienia obowiązku utworzenia krajowych biur, które by koordynowały i pomagały w korzystaniu

\footnotetext{
${ }^{54}$ Ibidem, s. 382.

${ }^{55}$ T. Buck, M. Wabwile, op. cit., s. 218.

${ }^{56}$ Ibidem.

${ }^{57}$ Ibidem.

${ }^{58}$ A. Szarek-Zwijacz, op. cit., s. 183.
} 
z procedury skargowej przed Komitetem Praw Dziecka. Jednak takie zobowiązanie także nie znalazło się w ostatecznej wersji Protokołu ${ }^{59}$.

Podczas tworzenia Protokołu kwestią dyskusyjną był również zakres udziału danego państwa w procedurze skargi przed KPD. Kilka delegacji opowiadało się za dużą ingerencją państwa w postępowaniu przed KPD. Ostatecznie przedstawiciele KPD, broniąc swojej niezależności i profesjonalizmu, wyrazili negatywną opinię w odniesieniu do tego projektu. Podkreślili ponadto, że tak duże kompetencje państw-stron proponowanych przez delegacje byłyby wyjątkiem na tle innych komitetów działających w ramach traktatowego systemu ochrony praw człowieka ONZ, który w żaden sposób nie spowodowałby skuteczności działania KPD ${ }^{60}$.

W trakcie prac nad trzecim Protokołem dyskutowano też o kwestii reprezentacji dziecka w postępowaniu przed KPD. Pojawiła się koncepcja zakładająca „skopiowanie” instytucji reprezentacji z krajowych przepisów. Z powodu oczywistych różnic $\mathrm{w}$ tym zakresie $\mathrm{w}$ ramach porządków prawnych przyszłych państw-stron protokołu zrezygnowano $\mathrm{z}$ tego pomysłu ${ }^{61}$. Warto w tym miejscu zaznaczyć, że w żadnej procedurze międzynarodowej, zarówno w ramach systemu traktatowego ochrony praw człowieka ONZ, jak i przed Europejskim Trybunałem Praw Człowieka, nie ma żadnych ograniczeń i wymogów odnoszących się do jednostek w aspekcie ich zdolności do składania skarg. Świadczy o tym możliwość złożenia takiej skargi przez osoby niepełnosprawne umysłowo na podstawie przepisów Protokołu dodatkowego do Konwencji o prawach osób niepełnosprawnych ${ }^{62}$. Ponadto w przypadku trzeciego Protokołu w art. $5^{63}$ użyto słowa ,jednostka", odnosząc się do podmiotów mogących składać skargę do Komitetu Praw Dziecka. Interpretacja tego zwrotu wskazuje, że z prawa do złożenia takiej skargi może skorzystać człowiek dorosły, ale także dziecko ${ }^{64}$. Dzieci, podobnie jak dorośli, w trakcie całej procedury mogą korzystać z pomocy profesjonalnych pełnomocników, których zadaniem jest jak najlepsze reprezentowanie ich interesów ${ }^{65}$.

Dodatkowo wiele sprzecznych opinii pojawiło się w kontekście postanowienia dotyczącego braku obowiązku bezwzględnej zgody ofiary naruszenia (dziec-

${ }^{59}$ T. Buck, M. Wabwile, op. cit., s. 209.

${ }^{60}$ Ibidem, s. 211.

${ }^{61}$ R. Smith, The Third Optional Protocol to the UN Convention on the Rights of the Child - Challenges Arising Transforming the Rhetoric into Reality, "International Journal of Children's Rights" 2013, Vol. 21, s. 312.

${ }^{62}$ Protokół fakultatywny do Konwencji o prawach osób niepełnosprawnych z dnia 13 grudnia 2016 r. przyjęty w Nowym Jorku, https://treaties.un.org/doc/source/docs/A_61_611_E.pdf [dostęp: 30.03.2017].

${ }^{63}$ P. Jaros, M. Michalak, op. cit., s. 312.

${ }^{64}$ A. Szarek-Zwijacz, op. cit., s. 171.

${ }^{65}$ Ibidem, s. 164. 
ka) na wszczęcie procedury. Zgodnie z art. $5 \S 2$ trzeciego Protokołu ${ }^{66}$ co do zasady wymagana jest zgoda podmiotu naruszenia. Tylko w wyjątkowych przypadkach osoba zgłaszająca takie naruszenie nie musi dysponować zgodą takiego podmiotu $^{67}$. Postanowienie to było krytykowane przede wszystkim z obawy o ewentualne manipulowanie dzieckiem $\mathrm{w}$ aspekcie wszczęcia postępowania skargowego przed KPD. Mimo to pozostawiono je w ostatecznej wersji Protokołu, chociaż budzi ono kontrowersje $\mathrm{w}$ niektórych środowiskach $\mathrm{w}$ wielu państwach-stronach Konwencji o prawach dziecka ${ }^{68}$.

Z powyższym zagadnieniem wiąże się także kwestia poufności postępowania skargowego przed KPD. Nie pozostawia wątpliwości zasada, że dane otrzymane przez KPD w ramach jego działalności na podstawie trzeciego Protokołu fakultatywnego nie powinny być ujawnione publicznie, co wielokrotnie podkreślano na etapie prac przygotowawczych. Tożsamość dziecka może być przedstawiana wyłącznie dla jego dobra i celów postępowania ${ }^{69}$. Zasada ta obejmuje również wnioski i wszelkie zalecenia kierowane przez KPD do państwa-strony trzeciego Protokołu w danej sprawie. Podczas przygotowywania projektu trzeciego Protokołu eksperci podkreślali, że poufności nie można utożsamiać z anonimowością. Żadne postępowanie przed KPD ani inicjująca je skarga nie może być anonimowa i musi określać tożsamość ofiary naruszenia, co wynika z art. 5 trzeciego Protoko$\mathrm{fu}^{70}$. Dla wzmocnienia tej zasady grupa robocza negatywnie ustosunkowała się do możliwości składania skarg zbiorowych przez podmioty krajowe.

Wątpliwości budziło poza tym ograniczenie czasowe wprowadzone w trzecim Protokole. W art. 7 Protokołu podmiot ma na złożenie skargi 1 rok od wyczerpania procedury krajowej ${ }^{71}$. Ze względu na szczególny obszar ochrony praw człowieka, jakim są prawa dzieci, postulowano zrezygnowanie z tego terminu. Organizacje pozarządowe kwestionowały jego wprowadzenie i podkreślały negatywny wpływ na faktyczną dostępność i skuteczność procedury skargi przed KPD ${ }^{72}$.

Kontrowersyjną kwestią na pewnym etapie prac była też forma składania zawiadomienia. Wielu przedstawicieli w grupie roboczej uważało, że powinna być to forma ustna, na wzór procedury na podstawie Konwencji o ochronie osób niepełnosprawnych ${ }^{73}$. Podkreślali, że byłoby to korzystne i uczyniłoby procedurę bardziej przyjazną dzieciom. Ostatecznie zdecydowano się, za czym opowiadała

${ }^{66}$ P. Jaros, M. Michalak, op. cit., s. 313.

${ }^{67}$ R. Smith, op. cit., s. 319.

${ }^{68}$ Ibidem, s. 320.

${ }^{69}$ T. Buck, M. Wabwile, op. cit., s. 211.

${ }^{70}$ P. Jaros, M. Michalak, op. cit., s. 312-313.

${ }^{71}$ Ibidem.

${ }^{72}$ T. Buck, M. Wabwile, op. cit., s. 213.

${ }^{73}$ Protokół fakultatywny do Konwencji o prawach osób niepełnosprawnych z dnia 13 grudnia 2016 r. przyjęty w Nowym Jorku, https://treaties.un.org/doc/source/docs/A_61_611_E.pdf [dostęp: 30.03.2017]. 
się m.in. Polska, na formę pisemną. Zwolennicy formy ustnej uznają to za jedną z największych wad trzeciego Protokołu. W związku z tym organizacje pozarządowe przedstawiły propozycję utworzenia specjalnego formularza. Stwarzałby on możliwość sprawnego oraz dostosowanego do wieku i dojrzałości dziecka złożenia skargi do KPD. Przyjęcie takiego rozwiązania w przyszłości wydaje się pożądane i spełniające oczekiwania zarówno zwolenników, jak i przeciwników ustnej formy składania zawiadomień ${ }^{74}$.

Procedury skargowe przewidziane w trzecim Protokole mają stanowić uzupełnienie krajowych procedur działających w tym obszarze oraz inspirację do tworzenia jeszcze skuteczniejszych rozwiązań. Mają w tym pomóc postanowienia (art. 15 trzeciego Protokołu) przewidujące międzynarodową współpracę i wzajemną pomoc państw-stron Konwencji o prawach dziecka ${ }^{75}$, przejawiające się również w aspekcie działań państw na podstawie trzeciego Protokołu do Konwencji.

Zaletą trzeciego Protokołu jest to, że stanowi on szansę dla zmiany mandatu KPD. Dotychczasowa praktyka okresowych, składanych co 2 lata, sprawozdań wszystkich państw-stron Konwencji i dwóch Protokołów dodatkowych w wielu wypadkach okazywała się mało skuteczna. Państwo w swoich kolejnych raportach często tylko powielało informacje z poprzednich, nie były one aktualizowane. Procedura ta sprowadzała rolę KPD do reagowania na dane zawarte w raporcie, na które KPD nie miał wpływu. Zmiana w świetle trzeciego Protokołu prowadzi do zwiększenia aktywnej roli KPD, który sam, po powzięciu odpowiedniej informacji, będzie decydował o przyszłych krokach podejmowanych w stosunku do danego państwa-strony.

Można mieć nadzieję, że naturalną konsekwencją rozpatrywania zawiadomień wnoszonych na podstawie nowych procedur zawartych $w$ trzecim Protokole fakultatywnym będzie rozwój orzecznictwa KPD. Obok dotychczasowych komentarzy i zasad ogólnych pojawi się szereg rozstrzygnięć w konkretnych sprawach. Dzięki temu społeczność międzynarodowa będzie miała szansę lepiej poznać i zrozumieć postanowienia Konwencji o prawach dziecka i jej Protokołów dodatkowych. Przykład regionalnych tego typu instytucji, takich jak Europejski Trybunał Praw Człowieka, pokazuje, że orzecznictwo na podstawie umów z zakresu praw człowieka, dość lakonicznie formułowanych, stanowi w praktyce bardzo dużą wartość.

\footnotetext{
${ }^{74}$ A. Szarek-Zwijacz, op. cit., s. 172-173.

${ }^{75}$ P. Jaros, M. Michalak, op. cit., s. 319-320.
} 


\section{PODSUMOWANIE}

Komitet Praw Dziecka powstał na podstawie Konwencji o prawach dziecka z dnia 20 listopada 1989 r. Jej druga integralna część stanowi sui generis statut KPD. Od początku swojego istnienia KPD funkcjonował w sześciu formach działalności mających za podstawowy cel ochronę praw dziecka przez: ich przestrzeganie w praktyce, odpowiednią interpretację i zastosowanie czy wypracowywanie najlepszych światowych rozwiązań. Po 2000 r. państwa-strony Konwencji zauważyły potrzebę nadania KPD nowych uprawnień, funkcjonujących dotąd $w$ innych tego typu komitetach. Wprowadzono zatem dwie procedury zawiadomień - indywidualnych i międzypaństwowych - oraz możliwość skorzystania z procedury wyjaśniającej, co jednocześnie stawia przed nim duże wyzwania. Przed KPD stoi zadanie jak najlepszego wykorzystania przyznanych mu instrumentów prawnych. Od tego, jak faktycznie będzie wypełniał swoje obowiązki, zależy jego skuteczność. Wydaje się, że KPD, aby zbudować silną pozycję na arenie międzynarodowej, powinien być bezstronny w swojej działalności i konsekwentny w orzekaniu. Dzięki temu będzie budził większe zaufanie, czego konsekwencją stanie się wzmocnienie współpracy z państwami-stronami trzeciego Protokołu, a co najważniejsze - wzmocnienie skuteczności kontroli przestrzegania ochrony praw dziecka na świecie.

\section{BIBLIOGRAFIA}

Balcerek M., Międzynarodowa ochrona praw dziecka, Warszawa 1988.

Beco G. de, The Optional Protocol to the Convention on the Rights of the Child on a Communications Procedure: Good News?, "International Human Rights Law Review" 2013, No. 367.

Buck T., Wabwile M., The Potential and Promise of Communications Procedures under the Third Protocol to the Convention on the Rights of the Child, "International Human Rights Law Review" 2013, Vol. 2.

Convention on the Rights of the Child Adopted by the General Assembly of the United Nations on 20 November 1989, https://treaties.un.org/doc/Publication/CN/1995/CN.138.1995-Eng.pdf [dostęp: 20.09.2017].

Gerber P., The New Optional Protocol to the Convention on the Rights of the Child. 10 things you should know, "Alternative Law Journal" 2012, Vol. 32(2).

Góralczyk W., Sawicki S., Prawo międzynarodowe publiczne w zarysie, Warszawa 2009.

Jaros P., Trzeci Protokól Fakultatywny do Konwencji - komentarz, [w:] Konwencja o prawach dziecka. Wybór zagadnień (artykuły i komentarze), red. S. Stadniczeńko, Warszawa 2015.

Jaros P., Michalak M., Prawa dziecka. Dokumenty ONZ, Warszawa 2015.

Kondratiewa-Bryzik J., Początek prawnej ochrony życia ludzkiego w świetle standardów międzynarodowych, Warszawa 2009.

Konwencja o prawach dziecka. Wybrane zagadnienia prawne i socjalne, red. T. Smyczyński, Warszawa 1994. 
Konwencja o prawach dziecka z dnia 20 listopada 1989 r. przyjęta w Nowym Jorku (Dz.U. z 1991 r., nr 120, poz. 526).

Kuryłowicz M., Wiliński A., Prawo rzymskie prywatne. Zarys wykładu, Warszawa 2008.

Lee Y., Communications procedure under the Convention on the Rights of the Child: $3^{\text {rd }}$ Optional Protocol, "International Journal of Children's Rights" 2010, Vol. 18(4),

DOI: https://doi.org/10.1163/157181810X527239.

Limsira P., Optional Protocol to the Convention on the Rights of the Child on a Communications Procedure, "Journal of East Asia and International Law" 2013, Vol. 1(8).

Łopatka A., Konwencja praw dziecka w Polsce, [w:] Prawa dziecka. Deklaracja i rzeczywistość, red. J. Bińczycka, Kraków 1999.

Michałowska G., Międzynarodowa ochrona praw dziecka, Warszawa 2016.

Międzynarodowy Pakt Praw Obywatelskich i Politycznych z dnia 19 grudnia 1966 r. przyjęty w Nowym Jorku (Dz.U. z 1997 r., nr 38, poz. 67).

Protokół fakultatywny do Konwencji o prawach dziecka w sprawie angażowania dzieci w konflikt zbrojny z dnia 25 maja 2000 r. przyjęty w Nowym Jorku (Dz.U. z 2007 r., nr 76, poz. 464).

Protokół fakultatywny do Konwencji o prawach dziecka w sprawie handlu dziećmi, dziecięcej prostytucji i pornografii z dnia 25 maja 2000 r. przyjęty w Nowym Jorku (Dz.U. z 2007 r., nr 91, poz. 608).

Protokół fakultatywny do Konwencji o prawach dziecka w sprawie procedury składania zawiadomień z dnia 19 grudnia 2011 r. przyjęty w Nowym Jorku.

Protokół fakultatywny do Konwencji o prawach osób niepełnosprawnych z dnia 13 grudnia 2016 r. przyjęty w Nowym Jorku, https://treaties.un.org/doc/source/docs/A_61_611_E.pdf [dostęp: 30.03.2017].

Prucnal M., Komitet Praw Dziecka i jego zadania, [w:] Konwencja o prawach dziecka. Wybór zagadnień (artykuły i komentarze), red. S. Stadniczeńko, Warszawa 2015.

Przyborowska-Klimczak A., Prawo międzynarodowe publiczne. Wybór dokumentów, Lublin 2008.

RPD, www.brpd.gov.pl [dostęp: 10.10.2017].

RPD, W sprawie ratyfikacji III Protokotu Fakultatywnego do Konwencji o Prawach Dziecka, http:// brpd.gov.pl/aktualnosci-wystapienia-generalne/w-sprawie-ratyfikacji-iii-protokolu-fakultatywnego-do-konwencji--0 [dostęp: 07.07.2017].

Smith R., The Third Optional Protocol to the UN Convention on the Rights of the Child-Challenges Arising Transforming the Rhetoric into Reality, "International Journal of Children's Rights" 2013, Vol. 21.

Stojanowska W., Dobro dziecka jako instrument wyktadni norm Konwencji o prawach dziecka oraz prawa polskiego i jako dyrektywa jego stosowania, [w:] Konwencja o prawach dziecka. Wybrane zagadnienia prawne i socjalne, red. T. Smyczyński, Warszawa 1999.

Szarek-Zwijacz A., Protokół fakultatywny do Konwencji o prawach dziecka dotyczacy procedury zawiadomień - rzeczywiste wzmocnienie ochrony praw dzieci?, [w:] Odpowiedzialność międzynarodowa $w$ zwiazku z naruszeniami praw człowieka i międzynarodowego prawa humanitarnego, red. M. Balcerzak, J. Kapelańska-Pręgowska, Toruń 2016.

UNICEF, Research and reports, www.unicef.org/reports [dostęp: 20.09.2017].

United Nations Treaty Series, Chapter IV: Human Rights, https://treaties.un.org/Pages/ViewDetails. aspx?src=TREATY\&mtdsg_no=IV-11-d\&chapter=4\&clang=_en [dostęp: 20.09.2017]. 
Pobrane z czasopisma Studia Iuridica Lublinensia http://studiaiuridica.umes.pl Data: 26/04/2023 07:26:34

Reforma Komitetu Praw Dziecka w świetle trzeciego Protokołu fakultatywnego...

\section{SUMMARY}

One of the agreements belonging to the United Nations Treaty on human rights is the Convention on the Rights of the Child, adopted on November 20, 1989. It is a fundamental document of the international protection of the rights of the child. On this basis, an organ was created to ensure the observance of the right in the Convention - the Committee on the Rights of the Child. In the later years three Optional Protocols were adopted. The first two concern substantive law - the Optional Protocol to the Convention on the Rights of the Child on the Involvement of Children in Armed Conflict and the Optional Protocol to the Convention on the Rights of the Child on the sale of child prostitution and child pornography of 25 May 2010. The Third Optional Protocol to the Convention on the Rights of the Child on a communications procedure of 19 December 2011 introduces the reform of the Committee on the Rights of the Child through the procedure of individual and interstate notifications. This article focuses on the analysis of the changes and attempts to assess their practical application.

Keywords: international protection of human rights; protection of the rights of the child; Convention on the Rights of the Child; Committee on the Rights of the Child; reform 